\title{
Risky sexual behavior and identity construction among adolescents in Ethiopia
}

\author{
Belay Tefera $^{1}$ and Missaye Mulatie ${ }^{2^{*}}$ \\ ${ }^{1}$ School of Psychology, Addis Ababa University, Sidst Kilo Campus, Addis Ababa, Ethiopia. \\ ${ }^{2}$ Department of Psychology, Gondar University, Addis Ababa, Ethiopia.
}

Received 6 December, 2013; Accepted 14 February, 2014

\begin{abstract}
Adolescents in Ethiopia are found to engage in a host of risky behaviors that lead to sexual and reproductive health problems including Human Immune Deficiency Virus/Acquired Immunodeficiency Syndrome (HIVIAIDS), unplanned pregnancy, and abortion; just to mention but a few. Quite a number of research investigations have been conducted to document on the factors that lead youth to these risky behaviors. However, these investigations focused to a greater extent on the external factors orchestrating risky ventures. There is a paucity of interest to examine the extent to which the internal, developmentally salient, and functionally overwhelming dimension of adolescent development, called "personal identity construction", structure risky orientations in young persons. This research was attempted to fill in this gap. It attempts to investigate if identity achievement can play the protective role against risky sexual behaviors among young people. Three hundred and two adolescent students were selected from three schools in North Gondar Administrative Zone. The results revealed that only some students had achieved their identity and yet a greater majority had experience of sexual intercourse at least once in their life. However, as compared to identity achievers, non-achievers were significantly more engaged in sexual intercourse, had sex with multiple partners including sex with commercial sex workers, engaged in casual sex, and failed to use birth control and condom in different sexual encounters. Therefore, significant proportion of identity non-achievers were more exposed to these risky behaviors than identity-achieved adolescents.
\end{abstract}

Key words: Risky, sexual behavior, identity construction, human immune deficiency virus/acquired immunodeficiency syndrome (HIVIAIDS), adolescents.

\section{INTRODUCTION}

Adolescence is a critical period of development of sexuality that in some instances may involve 'risky sexual practices' (Margaret and Lynn, 2000) leading to unwanted pregnancy, abortion, Human Immune Deficiency Virus/Acquired Immunodeficiency Syndrome (HIVIAIDS) and other sexually transmitted infections (Tewabe, 2009).
Available data indicate that adolescents and young adults are the age groups that are most at risk (Negash et al., 2003) to sexual and reproductive health problems to such an extent that these needs have emerged in more recent years as an issue of great concern for governments, civil societies, community-based organizations,

*Corresponding author. E-mail: mula te2002@yahoo.com.

Author(s) agree that this article rema in pemanently open access under the terms of the $\underline{C r e a t i v e ~ C o m m o n s ~ A t t r i b u t i o n ~}$ License 4.0 Intemational License 
and other stake holders (Tewabe, 2009). More specifically, findings from reviews of extensive research on HIVIAIDS, in young persons from developing countries, generally suggest that young people are at the center both in terms of new infections as well as being the greatest potential force for change if they can be reached with the right interventions (Auerbach et al., 2006)

The review of the effective and promising interventions for preventing HIV infection indicates that there is a large quantity of evidence from experimental and observational research as well as from practical real-world experiences both in developed and developing countries, in fact supporting the implementation and scale-up of a number of interventions and strategies (Auerbach et al., 2006).

At the same time, however, findings indicate that there is a need to continue to develop new and more effective interventions, while attending to a number of behavioral and social issues that cut across virtually all interventions designed to prevent the spread of HIV. Such conclusion naturally follows from a number of studies conducted in different countries in Africa reporting the disparity between young people's knowledge about HIVIAIDS and reported protected sexual behaviour (Hoffmann et al., 2006; Odutolu, 2005).

This would then invite a visit into some less emphasized (endogenous rather than exogenous) structures that give developmental overtone to researching risky sexual behaviors in adolescence. Development of personal identity is one such endogenous factor that basically structures the entire psychological functioning of young persons during the period of adolescence. This being the case, such major developmental concern of adolescence has, however, heeded little attention so far in researching risky adolescent ventures. Only few studies were conducted on identity development and any aspect of sexuality (Dunkel and Papani, 2005).

The same holds true with research studies in Ethiopia. There are only few local studies that show the importance of sexual experiences (either healthy or risky sexual behavior) in the process of identity formation among adolescents. Therefore, it is of paramount importance to investigate the issue of vulnerability to risky sexual behaviors of those (young persons) who are developmentally be set with identity exploration and definition but in a context of development where discussing about sex is considered in many cases as a cultural taboo, child socialization or parenting is stricter and authoritarian discouraging independence and risk taking particularly in girls, dating and pre-marital sex are as yet not welcomed, but regarded rather as shameful and an embarrassment to family, and the unwritten curriculum so far is of a nature, for example, that, a "good" adolescent is expected to be submissive and ignorant about and issues related to sex. Conforming to these expectations would, on the other hand, mean depriving the self of opportunities for development of personal identity.

There appears an apparent dilemma here: withholding sexual exploration for the purpose of avoiding sex-related health problems or letting adolescence without sense of personal identity. So, the main question is how to negotiate adolescents' identity exploration which is inevitable and health risk outcomes as a result of sexual explorations and experimentations. It is, in this regard, believed that fundamental to conduct a study on identity development to shed light on this question and in doing so develop an understanding of adolescent sexuality in a new light in our attempts to fight against the outcomes of unprotected sex. Hence, helping young people to explore identity alternatives in a systematic way and to consolidate a sense of identity among the alternatives is useful in prevention and intervention programming efforts. Moreover, having such knowledge is useful in developing and implementing prevention and intervention efforts of sexual-related to health problems.

This research was, therefore, conducted to assess how identity exploration, consolidation and formation would relate to vulnerability to risky sexual behavior among young people in North Gondar and suggest implications for intervention.

\section{MATERIALS AND METHODS}

\section{Participants and sampling}

There are a total of 36 lower secondary, 16 upper secondary (preparatory) and 3 post-secondary schools or colleges in the North Gondar Zone. Keeping issues of accessibility, feasibility and technical convenience closely in picture, the target population was delimited to educational institutions or schools; one school from each level: Dabat Secondary and Preparatory School, Fasiledes Preparatory School, Kola Diba Preparatory School, and Gondar College of Technical, Vocational Education and Training.

Initially, 310 young persons were sampled from these schools. However, the responses of eight participants were discarded for incompleteness of the filled-in questionnaire and hence 302 students' responses were found legible for analysis. About 180 (59.6) participants were males, while the rest $122(40.4 \%)$ were females. The number of participants considered in the sample was comparable across schools.

The procedure of sampling was such that the population of students in the North Gondar Zone was firstly stratified based on educational levels (secondary, preparatory and college levels) to ensure representation of young persons across ages. The three levels need to be represented in view of the fact that identity development is a process that spans over the years rather than being an event that happens in one specific stage. Besides, taking participants from different strata with different age levels is a powerful way to enhance external validity or generalizability of a study (Creasey, 2006). Accordingly, the study sites were further stratified by grade levels and one section was randomly selected from each grade as a final sampling frame. Besides, the 310 participants were recruited proportionally from the aforementioned four schools.

\section{Measures}

Two important measures were used for data collection: "Personal Identity Measure" and "Risky Sexual Behavior Measure". The Extended Measure of Ego Identity Status (Adams, 1989) was used 
Table 1. Identity status of respondents.

\begin{tabular}{lcc}
\hline Identity type & Frequency & Percent \\
\hline Identity achieved & 131 & 43.38 \\
Identity non-achieved & 171 & 56.62 \\
Total & 302 & 100 \\
\hline
\end{tabular}

to examine 'Personal Identity Status'. This scale attempted to determine the presence or absence of exploration and commitment in the areas of vocation, occupation, politics, life styles, recreational choices, friendship and gender roles. Exploration of identity requires a person to struggle or actively question so as to arrive at a decision about goals, values and beliefs on domains of identity status. Commitment, on the other side, involves making choice about identity domains or elements and engaging in implementation of already chosen components (vocational choice, religious beliefs, gender role attitudes, family roles and sexual expressions).

It consisted of a total of 64 items that required participants to rate themselves on a four point scale (strongly agree $=4$ and strongly disagree=1) regarding the extent to which they possessed the qualities expressed. Some of the items that were used to measure identity non-achievement included items like, "I do not think about dating much, I just kind of take it as it comes"; "I'm still exploring the many possibilities to find the right kind of friends for me". On the other hand, some of the items that were used to measures identity achievement included items like,"I have dated different types of people and know exactly what my own "unwritten rules" for dating are and who I will date; Based on past experiences, I have chosen the type of dating relationship I want now".

The 'Risky Sexual Behavior Measure' was composed of a checklist of eight items including casual sex, having sex with multiple partners, having paid sex and failure to use condom in such sexual activities (Russian Institute of Nutrition, 2001).

The reliability index of the items that were supposed to measure diffusion and foreclosure status were found to be 0.68 and 0.72 , respectively. In addition, the reliability of items on moratorium and achievement identity status subscales was found to be 0.73 and 0.83 , respectively. Overall, the foreclosure, moratorium and achievement subscales have good reliability. The wordings of some items on the diffusion subscale were modified for it has relatively lower reliability value. The reliability of the second tool designed to measure sexual practices was also checked. The computed reliability coefficient of items that assess sexual practices of participants was found to be 0.84 . This is a very good reliability index to measure the construct, sexual experience.

The instruments were also checked for content relevance and cultural sensitivity, translated into the native language of respondents, and then pretested. Some defective items were discarded; few other items that lacked in clarity were rewritten. The final questionnaire was administered separately at each school by pulling up sample participants from all the grades together.

Once the data were secured, analysis begun by determining the identity status of individuals. This was done by employing 'mediansplit technique (Balistreri et al., 1995). That is, after summing up the total scores of each participant on the exploration and commitment dimensions, it was found out that a median score of 65.5 and 62 were used as cut of points, respectively for exploration and commitment dimensions to categorize scores into identity achievement and non-achievement. Accordingly, participants who scored above the median scores on both exploration and commitment dimensions were defined as 'identity achievers'. But, those participants who did not score above the median scores either on one or both exploration and commitment dimensions were defined as 'identity non-achievers". Assumption-free statistic, Chi- square $\left(\chi^{2}\right)$, was used to test the significance of association that identity status has with sexual experiences, and other safe sex practice measures.

\section{RESULTS}

The analysis was started by examining the status of participants on identity achievement and sexual experiences of the participants. This analysis serving as a foundation, the next analysis shall attempt to determine the association between identity status and sexual experiences. The third part shall attempt to examine the association between identity status and risky sexual practices.

Regarding identity development, there are two defining criteria to categorize individuals into different identity status. These criteria are the presence or absence of exploration of alternatives and commitments in different domains such as vocational plans, religious beliefs, political beliefs, dating, sexuality, friendship, family roles and sex role preferences. Identity achievement entails then engagement in exploration and experimentation with commitment to such engagements. The summary data on Table 1 depicts the proportion of cases that were found to exhibit achievement of identity as a result of this sustained exploration and commitment.

As shown in Table 1, only $43.38 \%$ have achieved their identity whereas more than half $(56.62 \%)$ were identity non-achievers. This shows that many young persons in rural cities of the Amara region are only in the process of forming or consolidating their identity and identity achievement is more likely to extend to the age normally designated for adulthood.

Part of identity development in adolescence is definition of sexuality. This search for one's sense of sexuality will implicate on a number of sexual activities including dating and sexual intercourse. The data summarized in Table 2 shows a significantly more number of boys were engaged in sexual activities than girls $\left(\chi^{2}=10.85, \mathrm{P}<0.05\right)$. That is, half $(50 \%)$ of male participants had involved in sexual activity at least once in their life as compared to less than half $(40 \%)$ female participants who had the same experiences. The onset of sexual intercourse (Table 4) was reported to be 18.16 years. It can also be seen on Table 2 that out of those who had some kind of sexual experience, a significantly higher number of boys had relationship with more than one partner, while the majority of girls had relationship only with one partner $\left(\chi^{2}=8.23\right.$, $P<0.05)$. In the same way, we can still understand from Table 2 that the duration of relationship for boys is significantly lower than girls $\left(\chi^{2}=8.23, P<0.05\right)$.

\section{Identity achievement and sexual experiences}

Table 3 shows that there is a significant difference in sexual experience between identity achievers and nonachievers $\left(\chi^{2}=27.66, \mathrm{P}<0.05\right)$. Out of the total of 171 experiences as compared to the $31.30 \%$ of the identity 
Table 2. Sexual experiences by sex.

\begin{tabular}{|c|c|c|c|c|c|c|c|}
\hline \multirow{3}{*}{ Sexual experience } & & \multicolumn{4}{|c|}{ Sex } & \multirow{3}{*}{ df } & \multirow{3}{*}{$\chi^{2}$} \\
\hline & & \multicolumn{2}{|c|}{ Male } & \multicolumn{2}{|c|}{ Female } & & \\
\hline & & Frequency & Percent & Frequency & Percent & & \\
\hline \multirow{3}{*}{$\begin{array}{l}\text { Ever been involved } \\
\text { in sexual activities }\end{array}$} & Yes & 91 & 50.4 & 40 & 35.71 & \multirow{3}{*}{1} & \multirow{3}{*}{$10.85^{\star}$} \\
\hline & No & 57 & 49.6 & 82 & 64.29 & & \\
\hline & Total & 180 & 100 & 122 & 100 & & \\
\hline \multirow{3}{*}{ Number of partners } & Single (one partner) & 37 & 40.65 & 26 & 65 & \multirow{3}{*}{1} & \multirow{3}{*}{$8.23^{*}$} \\
\hline & Multiple (two or more partners) & 54 & 59.35 & 14 & 35 & & \\
\hline & Total & 91 & 100 & 40 & 100 & & \\
\hline \multirow{3}{*}{$\begin{array}{l}\text { Duration or term of } \\
\text { relationship }\end{array}$} & Long(> 6 weeks) & 34 & 37.4 & 33 & 82.5 & \multirow{3}{*}{1} & \multirow{3}{*}{$21.72^{\star}$} \\
\hline & Short $(<6$ weeks $)$ & 57 & 62.6 & 7 & 17.5 & & \\
\hline & Total & 91 & 100 & 40 & 100 & & \\
\hline
\end{tabular}

${ }^{*} \mathrm{P}<0.05$.

Table 3. Proportion of those who ever had sexual intercourse by identity status.

\begin{tabular}{lcccc}
\hline Identity Status & Frequency & Percent & df & $\chi^{2}$ \\
\hline Achievers & 41 & 31.3 & 1 & $27.6^{\star}$ \\
Non-achievers & 90 & 52.63. & & \\
\hline
\end{tabular}

*P $<0.05$.

Table 4. Onset of sex in years.

\begin{tabular}{lccc}
\hline Identity status & Min & Max & Mean \\
\hline Achievers & 15 & 22 & 18.25 \\
Non- achievers & 14 & 20 & 18.1 \\
Total & 14 & 20 & 18.16 \\
\hline
\end{tabular}

achievers. However, the average age of onset of sex for the identity achievers and non-achievers group appears comparable (18.25 and 18.1 years, respectively) as indicated in Table 4.

The basic question is "how far identity definition of young persons is associated with risky sexual experiences?". When we see number of partners in life time, the Chi- Square test shows significant difference between identity achievers and non-achievers $\left(\chi^{2}=4.56\right.$; $p<0.05$ ). Out of 41 sexually engaged identity achieved participants, only some $(29.27 \%)$ had multiple (more than one) sexual partners. In contrast, of the total 90 sexually engaged non-achievers, more than half $(57.78 \%)$ had single sexual partner. This shows that, those participants who did not achieve their identity were engaged with multiple sexual partners much more than identity achievers. The other interesting issue pertains to the extent to which identity status is associated with safe sex; mainly condom use and use of birth control (Table 5).
Moreover, as shown in Table 5, there is a significant difference between identity achiever and non- achiever groups in terms of use of birth control during sexual intercourse $\left(\chi^{2}=8.67, \mathrm{P}<0.05\right)$. A large proportion of identity non-achievers (64.45\%) did not use any birth control in their sexual relationships as compared to identity achievers $(26.85 \%)$. With respect to casual sexual experience, there is again a significant difference between identity achiever and identity non-achiever groups $\left(\chi^{2}=5.75, P<0.05\right)$. The proportion of identity non-achievers (48.89\%) having casual sexual encounters was significantly higher than the proportion of identity achievers (46.34\%) who did the same. Casual sex is also expressed in adolescents' failure to use condom. It can be observed in the same table that only small proportion of identity non-achievers used condom when they had casual sex. In contrast, relatively lower proportion of participants who had achieved their identity failed to use condom in casual sex than those of identity nonachievers $\left(\chi^{2}=5.66, P<0.05\right)$.

Finally, the previous table (Table 5 ) still shows that there is a significance difference between identity achievers and non-achievers in the extent of engagement in commercial sex $\left(\chi^{2}=7.35, P<0.05\right)$. Only few $(12.20 \%)$ of identity achieved participants had commercial sex, whereas $26.67 \%$ of identity non-achievers had comer-cial sexual experience. And, about half (50\%) of identity nonachievers used condom when they had commercial sex. 


\section{DISCUSSION}

Personal identity formation occurs as individuals develop a secure and enduring sense of self that encompasses an integrated set of personal interests, values, goals and commitments. Adolescence and youth are the periods in which individuals are expected to achieve a sense of personal identity. The developmental progression or movement from less advanced identity status to a higher identity status is found to be a function of age (Macinnon, 2002). It was found that the proportion of identity diffusion declines, while the proportion of identity achievement increases with age (Marcia, 1993). It was observed that foreclosure or premature identity achievement is the most frequently observed during high school years and it declines with increasing age (Marcia, 1993). Similarly, in one study (Muuss, 1996), 68 and $32 \%$ of 12 years old participants were found to have identity diffusion and foreclosure, respectively. However, at the age of 24, more than half $(56 \%)$ achieved their identity (Muuss, 1996). The findings of this study seem to show that only some students have achieved identity. In fact, previous studies have also shown that not all adolescents attain identity (Louden, 2005; Marcia, 1993; Waterman, 1993).

While identity achievement obviously gets likely with age, progression to a higher identity status is still a function of culture implying that beyond the factor of age, the situation of identity development may take a different picture for individuals of different cultural backgrounds. Cross cultural studies have, for example, shown that living in a collectivist contexts, like that of Ethiopia, tends to struggle to integrate their own individual identity with the norm of the collectivist society which emphasizes conformity, communal rules and close relationships (Gardiner and Kosmitzki, 2008.)

Likewise, the Ethiopian collectivist culture, unlike the individualistic culture of the Western World, demands adolescents to conform to the values, norms and cultural standards of the society. This cultural scenario seems to give a reduced space for individuation. In Ethiopia, it seems that rather than achieving identity through judging oneself as an individual, much emphasis is given to social and cultural norms. Adolescents are not often allowed and supported to search their own identity, but are rather forced to strictly follow parental religion, vocation, political thought and belief.

An important dimension of identity construction is sexual definition. When it comes to status on sexuality, it was found that nearly half of the participants had experienced sexual intercourse at least once in their life. Cross-national studies conducted in Sub-Sahara Africa countries have also shown high prevalence of sexually active adolescents as compared to developed nations (Gueye et al., 2004; Gupta and Mahy, 2004; King, 1996; Negussie et al., 2002). It was noted that at the age of 20 , about $80 \%$ of adolescents were sexually active in SubSahara Africa as compared to $75 \%$ in developed nations
(Negussie et al., 2002). Surprisingly, many adolescents have their first sexual experiences before the age of ten (Ateka, 2001).

In fact, the average age of the onset of sex in this study (18.15 years) was found to be higher than those previously reported: 16.38 and 16.5 years for girls and 17.4 years for boys in Addis Ababa (Amuyunzu-Nyamongo et al., 1999).

It was also observed in the present study that significantly more number of boys had sexual experience once in their life with more number of sexual partners and shorter period of relationship than girls. Similarly, much more than females, male students in some selected high schools in Addis Ababa were engaged in sexual practices (Feben, 2005). According to Social Role Theory, sex differences in sexual activities have been attributed to gender role differences prescribed by society and the difference is more pronounced in cultures where more traditional gender roles are practiced (Dunkel and Papani, 2005).

The question is then "how is identity definition related to sexual activity?" Obviously, identity formation requires young people to engage in the process of exploration and experimentation. It is during adolescence and youth that individuals start experimenting on sex and engage in different sexual activities (like masturbation, fantasies, kissing, fondling and sexual intercourse), because sexuality is considered as one way of exploring who they are (Furman and Shaffer, 2001; Steinberg, 1993).

Such exploration is in fact normative during adolescence, but may be associated with risky behaviors (Schulenberg and Maggs, 2010) or instability as well as potentially health-compromising experimentation of sex that may lead identity non-achievers to choose risky behaviors based on anticipated immediate consequences, even in the presence of negative long-term consequences (Schulenberg and Maggs, 2002).

Despite the possibility for such serious consequences, exploration and experimentation of sexual activities may also serve important and constructive functions in helping adolescents make friends or explore personal identities and clarify who they are and what they should be. As a result, some have questioned the wisdom of attempting to limit experimentation and exploration, because this may leave individuals without a self-determined commitment to an identity and to personal values (Schulenberg and Maggs, 2002).

The findings of this study seem to support the importance of identity achievement in the sense that significantly more number of those who did not achieve their identity had ever involved in sexual intercourse at least once in their life as compared to identity achievers (Waterman, 1993). The problem with such sexual experience was that it appeared to be risky: identity nonachievers were found to lack in commitment, thus having significantly more number of sexual partners, were engaged in casual and commercial sex significantly higher 
Table 5. Number of sexual partners, casual sex, commercial sex without condoms and use of birth control by identity status.

\begin{tabular}{|c|c|c|c|c|c|c|}
\hline \multirow{3}{*}{ Issue } & \multicolumn{6}{|c|}{ Identity status } \\
\hline & \multicolumn{2}{|c|}{ Achievers } & \multicolumn{2}{|c|}{ Non- achievers } & \multirow{2}{*}{$\mathbf{d f}$} & \multirow{2}{*}{$\chi^{2}$} \\
\hline & Frequency & Percent & Frequency & Percent & & \\
\hline Those having casual sex & 19 & 46.34 & 44 & 48.89 & 1 & $5.75^{\star}$ \\
\hline Those not using condom in casual sex & 11 & 57.90 & 34 & 77.28 & 1 & $5.66^{\star}$ \\
\hline Those having commercial sex & 5 & 12.20 & 24 & 26.67 & 1 & $7.35^{\star}$ \\
\hline Those failing to use birth control & 11 & 26.83 & 58 & 64.45 & 1 & $8.67^{\star}$ \\
\hline
\end{tabular}

${ }^{*} \mathrm{P}<0.05$

higher than the identity achievers, and had shorter sexual relationships (that increases the likelihood of sexually transmitted diseases (STDs) and reproductive health problems like HIVIAIDS) and yet significantly relatively smaller number of them were using birth control including condom use.

Evidences also indicate that individuals characterized by lack of commitment (have not achieved identity) likely to have more than one (multiple) sexual partner and often shallow less intimate and casual lasting for a short period (Orlofsky, 1993). On the other hand, identity achievement is found to protect young persons from unprotected and casual sex which lead to health problems (MatickaTyndale and Brouillard-Coyle, 2006; Schulenberg and Maggs, 2010), promote deeper, intimate, and enduring sexual relationship with a partner (Karl, 1989), and correlate positively with lower incidence of health compromising behaviors (risky sexual behavior) and negatively with unprotected, casual, and intoxicated sex (Schulenberg and Maggs, 2002). Identity achievement that involves consistency of self across time and place (identity consolidation) may potentially protect young people from casual and unprotected sex (Schulenberg and Maggs, 2002).

\section{Conclusion}

As compared to those identity achiever young persons, achieve non achievers had ever involved in sexual intercourse at least once in their life. In addition, identity non-achievers had more number of sexual partners and casual sexual relationships than identity achievers. Moreover, much more than identity achievers, identity non achievers were engaged in commercial sex which exacerbates their vulnerability to STDs including HIVIAIDS. Hence, identity achievement or consolidation (consistency of self across time and place) likely reduces vulnerability of young persons from HIVIAIDS and other STDs.

\section{Conflict of Interests}

The author(s) have not declared any conflict of interests

\section{ACKNOWLEDGEMENTS}

The authors gratitude goes to Atinkut Zewdu, Micheal lyasu, Mohammed Mekonnen and Takle Adino for their support during data collection phase of the study. Last but not the least, they want to thank the participants for their willingness to participate in the study.

\section{REFERENCES}

Adams R (1989). The Objective Measure of Ego Identity Status: A Reference Manual. Retrived on 12, December 2008 at http://www.uoguelph.ca

Amuyunzu-Nyamongo M, Tendo-Wambua L, Babishangire B, Nyagero J, Yitbarek N, Matasha M, Omurwa T (1999). Barriers to behavior change as a response to STD including HIVIAIDS: The East Africa Experience. In J. C.Caldwell, et al (Eds.), Resistance to Behavioural Change to Reduce HIVIAIDS Infection in Predominantly Heterosex.ua Epidemics in Third World Countries Canberra: Health Transition Centre.

Ateka G (2001). Factors in HIVIAIDS Transmission in Sub-Saharan Africa. Bulletin of the World Health Organization. 79 (12).

Auerbach JD, Hayes R, Kandathil S (2006). Overview of Effective and Promising Interventions to Prevent HIV infection. In Ross David A., Dick, Bruce and Ferguson (Edrs), Preventing HIVIAIDS in young people: A Systematic Review of the Evidence from Developing Countries. 43-78.

Balistreri E, Busch-Rossnagel NA, Geisinger KF (1995). Development and Preliminary Validation of the Ego Identity Process questionnaire. J. Adolescence. 18:179-192.

Creasey G (2006). Research Methods in Life Span Development. New York: Pearson Education, Inc, Danney, N, W. (1992). Human Sexuality ( $2^{\text {nd }}$ ed). U S A: Nosby Year book inc,

Furman W, Shaffer L (2001). The Role of Romantic Relationships in Adolescent Development: Theory, Research and Practical Implications. University of Danver: Institute of Mental Health, (Retrived on 10, October 2008. http://www.du.edu)

Gardiner C, Kosmitzki H (2008). Lives Across Cultures: Cross cultural human development USA.

Gueye M, Castle S, Kante MK (2001). Time of First Intercourse among Malian Adolescents. Sexual Behavior of Adolescents in Contemporary Sub-Sahara Africa: United Kingdom: The Edwin Mellen Press, Ltd.

Gupta N, Mahy M (2004). Sexual Initiation among Adolescent Girls and Boys: Trends and Differentials in Sub Sahara Africa. Sexual Behavior of Adolescents in Contemporary Sub-Sahara Africa. United Kingdom: The Eduin Mellen Press, Ltd.

Hoffmann O, Boler T, Dick B (2006). Achieving the Global Goals on HIV among Young People most at Risk in Developing Countries: Young Sex Workers, Injecting Drug Users and Men Who have Sex with Men. In Ross David A., Dick, Bruce and Ferguson (Edrs), Preventing 
HIVIAIDS in Young People Preventing HIVIAIDS in young people: A Systematic Review of the Evidence from Developing Countries. WHO Technical Report Series 938:287-342.

Karl M (1989). Identity and Sexual Practice among College Students. Retrieved on 18, December 2008. http://www. autoronto.ca)

Macinnon J (2002).Concurring Patterns of Women's Identity Status, Attachment Style and Understanding of Children's Behavior. Canada: International Society for the Study of Behavioral Development,

Marcia J (1993). Ego Identity Status. A Book for Psychological Researches. New York: Spring Verlage.

Margaret T, Lynn R (2000). Risky Sexual Behavior among Adolescent Women. J. the Society of Pediatric Nurses, (Retrieved on 14, December 2010 at http://www.accessmylibrary.com)

Maticka-Tyndale E, Brouillard-Coyle C (2006). The Effectiveness of Community interventions targeting HIV and AIDS Prevention at Young people in Developing Countries. In: Ross David A., Dick, Bruce and Ferguson (Eds), Preventing HIVIAIDS in young people A Systematic Review of the Evidence from Developing Countries. WHO Technical Report Series 938:243-386.

Muuss E (1996). Theories of Adolescence. New York: McGraw Hill Camp, Inc.

Negash Y, Gebre B, Benti D, Bejiga M (2003). A community based study on knowledge, Attitude and Practice (KAP) on HIVIAIDS in Gambella Town, Western Ethiopia. Ethiopian J. Health Dev. 17(3):205-213.

Negussie T, Sundby J, Holm-Hansen C, Bjune G ( 2002). HIV prevalence and socio-cultural contexts of sexuality among youth in Addis Ababa, Ethiopia. Ethiop. J. Health Dev.16(2):139-145
Odutolu O (2005). Convergence of Behaviour Change Models for AIDS Risk Reduction in Sub-Saharan Africa. Int J. Health Plann. Manage. 20:239-252.

Orlofsky J (1993). Intimacy Status. A Book for Psychological Researches. New York: Spring Verlage,.

Dunkel CS, Papani DR (2005). The Role of Ego Identity Status in Mating Preference. (Retrieved from http://www.encyclpedia.com).

Russian Institute of Nutrition (2001). Sexual Behavior questionnaire: Longitudinal Monitoring Survey. University of North Carolina at Chapel Hill. Institute of Sociology, Russian Academy of Sciences.

Schulenberg J, Maggs JA (2002).Developmental Perspective on Alcohol Use and Heavy Drinking during Adolescence and the Transition to Young Adulthood. Survey Research Center, Institute for Social Research and Department of Psychology, University of Michigan.

Steinberg L (1993). Adolescence. Toronto: McGraw-Hall Inc.

Tewabe Y (2009). Education, HIVIAIDS, and Sexual Reproductive Health: Exploring the Unmet Information Needs of Young People: The Case of Addis Ababa and Bahir Dar, Ethiopia.

Waterman A (1993). Ego Identity. New York: Spring Verlage. 